OPEN ACCESS

Edited by:

Antonio Serrano,

Hospital Universitario 12 De Octubre,

Spain

Reviewed by:

Jason S. Knight,

University of Michigan, United States

Daniel Pleguezuelo,

Hospital Universitario 12 De Octubre,

Spain

*Correspondence:

Maria G. Tektonidou mtektonidou@gmail.com; mtektonidou@med.uoa.gr

Specialty section:

This article was submitted to Autoimmune and Autoinflammatory

Disorders,

a section of the journal

Frontiers in Immunology

Received: 11 October 2018

Accepted: 22 February 2019

Published: 15 March 2019

Citation:

Palli E, Kravvariti E and Tektonidou MG (2019) Type I Interferon Signature in Primary Antiphospholipid Syndrome: Clinical and Laboratory Associations. Front. Immunol. 10:487. doi: 10.3389/fimmu.2019.00487

\section{Type I Interferon Signature in Primary Antiphospholipid Syndrome: Clinical and Laboratory Associations}

\author{
Eleni Palli, Evrydiki Kravvariti and Maria G. Tektonidou*
}

Joint Academic Rheumatology Program, First Department of Propaedeutic Internal Medicine, School of Medicine, National and Kapodistrian University of Athens, Athens, Greece

Background: Increased expression of type I interferon (IFN)-regulated genes has been described in blood and tissue cells from patients with systemic lupus erythematosus (SLE) and other rheumatic disorders. Only isolated studies have examined the type I IFN gene expression in antiphosholipid syndrome (APS), while efforts to evaluate associations with APS-related factors are scarce.

Objective: Our aim was to investigate the type I IFN signature in patients with primary APS (PAPS), SLE/APS, and SLE in comparison with healthy controls, and to evaluate associations with disease-related characteristics.

Methods: We measured the type I IFN score, derived from relative expressions of three IFN-inducible genes (MX-1, IFIT-1, and IFI-44) in peripheral blood mononuclear cells from 55 patients with PAPS, 34 with SLE/APS, 48 with SLE, and 28 controls. In patients with PAPS, we performed multivariate regression to examine associations of type I IFN score with their clinical, laboratory and treatment characteristics.

Results: Type I IFN score was increased in all patient groups vs. controls $(p=0.028$, $p=0.027, p=0.028$ for PAPS, SLE/APS, and SLE, respectively). IFI-44 had the most pronounced expression. In patients with PAPS, multivariate linear regression revealed positive associations of type I IFN score with female gender (b-coefficient $=0.49 ; 95 \% \mathrm{Cl}$ $0.04,0.94 ; p=0.034$ ) and IgG or IgM anti- $\beta 2 \mathrm{GPI}$ antibodies (b-coefficient $=0.53 ; 95 \% \mathrm{Cl}$ $0.10,0.96 ; p=0.017$ ), and negative associations with age (b-coefficient $=-0.02 /$ year; $95 \% \mathrm{Cl}-0.04,-0.01 ; p=0.027)$ and hydroxychloroquine use (b-coefficient $=-0.51$; 95\% Cl-0.96, $-0.06 ; p=0.027)$.

Conclusion: Type I IFN score is increased in PAPS and correlated positively with anti- $\beta 2 \mathrm{GPI}$ antibodies and negatively with hydroxychloroquine use.

Keywords: antiphospholipid syndrome, systemic lupus erythematosus, type I Interferon signature, type I Interferon score, antiphospholipid antibodies, anti-b2-glycoprotein I antibodies, hydroxycloroquine

\section{INTRODUCTION}

Antiphospholipid syndrome (APS) is a systemic autoimmune disease characterized by recurrent venous and/or arterial thrombotic events and/or obstetric complications and the presence of antiphospholipid antibodies (aPL) including anti-cardiolipin antibodies (aCL), anti-beta2-

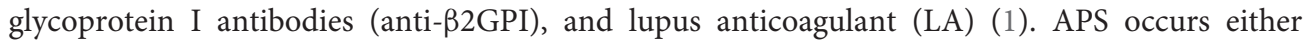


as primary APS (PAPS) or secondary APS, when it is associated with other autoimmune diseases, mainly systemic lupus erythematosus (SLE/APS). Approximately 30-40\% of SLE patients have positive aPL and almost one third of them develop APS $(1,2)$. In addition to well-characterized thrombotic events, other manifestations such as thrombocytopenia, livedo reticularis, valvular disease, APS nephropathy, or neurological disorders such as epilepsy and cognitive dysfunction may occur in APS, defined as non-criteria APS manifestations (3-5). Accordingly, in addition to thrombogenic mechanisms, aPLmediated inflammatory processes have also been identified in APS, and emerging therapies associated with these inflammatory pathways include hydroxychloroquine, B-cell targeted therapy, complement inhibition, peptide therapy, mTOR inhibitors, and others (6).

Type I interferons (IFNs) are cytokines that have various effects on innate and adaptive immune cells and have been implicated in the pathogenesis of a number of systemic autoimmune diseases including SLE, Sjögren's syndrome, rheumatoid arthritis, systemic sclerosis and myositis (7-11). Gene expression profiling data from patients with SLE have shown high messenger RNA transcripts of genes regulated by type I IFN, also known as IFN signature, that correlated with clinical and laboratory indices of lupus activity in several studies $(12,13)$. These findings have spurred research evaluating type I IFN-blocking agents as therapeutic alternatives in SLE (14). Only a few studies have addressed the question of IFN-inducible gene expression in PAPS and SLE/APS (15-17). However, most studies had a small sample size and only one attempted to correlate the type I IFN signature to disease-related characteristics of patients with PAPS (17).

The aim of this study was to compare the type I IFN signature in peripheral blood mononuclear cells (PBMCs) from patients with PAPS, patients with SLE/APS, patients with SLE not fulfilling the classification criteria for APS, and healthy individuals. We also evaluated potential associations between type I IFN signature and several clinical, laboratory and treatment characteristics of patients with PAPS.

\section{MATERIALS AND METHODS}

Consecutive adult patients with PAPS and age-matched patients with SLE/APS and SLE/non-APS followed in our department, were included in the study. Healthy individuals matched to PAPS patients by age distribution were recruited using brochures in the hospital and local community centers. Patients with APS (either PAPS or SLE/APS) fulfilled the updated Sapporo classification criteria (1), and patients with SLE met the updated ACR classification criteria for SLE (18). Candidates with active infection or hospitalization within the previous month, pregnancy, or history of malignancy, were excluded. The study protocol was approved by the local IRB ("Laikon Hospital Scientific Council") and all participants provided written informed consent.

At the study visit, all patients underwent thorough clinical and laboratory evaluation and their medical records were reviewed. For patients with APS, we recorded the details of prior thrombotic events (number, type, location) and/or obstetric complications establishing the diagnosis of APS, as well as the presence of non-criteria clinical manifestations as defined by the updated Sapporo classification criteria for APS (1). For patients with SLE, we recorded disease activity using the Systemic Lupus Erythematosus (SLE) Disease Activity Index--2000 (SLEDAI-2K), as well as history of major SLE complications, including nephritis and CNS involvement. Medication use was reviewed and recorded including corticosteroids, hydroxychloroquine, immunosuppressives (cyclophosphamide, azathioprine, mycophenolate mofetil, methotrexate, leflunomide, and cyclosporine), antiplatelets, oral anticoagulants, and statins. Patients receiving biologic agents such as $\mathrm{B}$ cell depletion and adalimumab were excluded.

Blood samples were drawn from patients for immunologic tests including antinuclear antibodies, anti-dsDNA, anti-Sm, anti-Ro/SSA and anti-La/SSB antibodies, C3 and C4 levels,

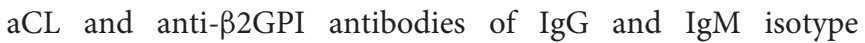
using standard ELISA (1), and LA measured according to Scientific Standardization Subcommittee (SSC) on Lupus Anticoagulant/Phospholipid Antibodies guidelines (19). Additional 8-10 mL samples were collected from all participants for the isolation of PBMCs using Lymphoprep (Stem Cell Technologies) as the density gradient medium, according to the manufacturer's instructions.

Total RNA was extracted from PBMCs using Trizol reagent (Ambion, Life Sciences, USA) according to standard procedure. RNA concentration and quality was determined by spectrophotometry (Biospec Nano, Japan). Total RNA was transcribed into cDNA, which was then quantified by Quantitative Real-Time PCR (qRT-PCR) reaction as previously described (20). Three genes typically induced by type I IFN $(10,16,20)$ were selected: myxovirus (influenza virus) resistance 1 (MX-1), interferon-induced protein with tetratricopeptide repeats 1 (IFIT-1) and interferon-induced protein 44 (IFI44). The levels of mRNA expression of type I IFN induciblegenes were determined based on the expression value of the glyceraldehyde phosphate dehydrogenase (GAPDH) reporterhousekeeping gene. Type I IFN score, was defined as the sum of relative expressions of MX-1, IFIT-1, and IFI-44 and calculated as previously described $(20,21)$. Type I IFN score was considered high if it exceeded the mean $+2 *$ standard deviation $(\mathrm{SD})$ value of the control group.

\section{Statistical Analysis}

Between-group comparisons were tested using the KruskalWallis and Mann-Whitney tests for continuous data, and Chi2 tests for nominal data. The Shidak-Holm method was used for correction of $p$-values for multiple comparisons. For patients with PAPS, we used the Mann-Whitney test to assess univariate associations of type I IFN score with nominal disease-related factors, and age as a binary variable, dichotomized on the median of PAPS group. We then applied linear regression to investigate multivariate associations of logtransformed type-I IFN score with clinical, laboratory and treatment characteristics of patients with PAPS. We applied 
TABLE 1 | Baseline characteristics of study participant groups.

\begin{tabular}{|c|c|c|c|}
\hline & $\begin{array}{l}\text { PAPS } \\
n=55\end{array}$ & $\begin{array}{c}\text { SLE/APS } \\
n=34\end{array}$ & $\begin{array}{c}\text { SLE } \\
n=48\end{array}$ \\
\hline Age (years, mean $\pm S D$ ) & $44.6 \pm 13.2$ & $45.4 \pm 11.5$ & $47.4 \pm 16.7$ \\
\hline Female gender $[n,(\%)]$ & $34(62)$ & $28(82)$ & $45(94)$ \\
\hline $\begin{array}{l}\text { Disease duration (years, } \\
\text { mean } \pm \text { SD) }\end{array}$ & $7.6 \pm 7.5$ & $11.3 \pm 9.3$ & $9.6 \pm 7.7$ \\
\hline Thrombotic events [n, (\%)] & $48(87)$ & $31(91)$ & $2(4)$ \\
\hline Venous thrombosis [n, (\%)] & $25(46)$ & $19(56)$ & $1(2)$ \\
\hline Arterial thrombosis $[n,(\%)]$ & $33(60)$ & $15(44)$ & $1(2)$ \\
\hline $\begin{array}{l}\text { Both arterial and venous events } \\
{[n,(\%)]}\end{array}$ & $10(18)$ & $4(12)$ & $0(0)$ \\
\hline CVA $[n,(\%)]$ & $18(33)$ & $12(35)$ & $0(0)$ \\
\hline $\begin{array}{l}\text { Recurrent thrombotic events } \\
{[n,(\%)]}\end{array}$ & $23(42)$ & $13(38)$ & $1(2)$ \\
\hline $\begin{array}{l}\text { Obstetric APS complications [ } n \text {, } \\
\text { (\% among women)] }\end{array}$ & $14(41)$ & $9(32)$ & $0(0)$ \\
\hline $\begin{array}{l}\text { Non-criteria APS manifestations } \\
{[n,(\%)]}\end{array}$ & $18(33)$ & $16(47)$ & - \\
\hline Corticosteroid use [n, (\%)] & $0(0)$ & $15(44)$ & $29(60)$ \\
\hline Immunosuppresives use [n, (\%)] & $0(0)$ & $18(53)$ & $19(40)$ \\
\hline Hydroxychloroquine use [n, (\%)] & $29(53)$ & $25(74)$ & $39(81)$ \\
\hline Antiplatelet use $[n,(\%)]$ & $28(51)$ & $15(44)$ & $19(40)$ \\
\hline Statin use $[n,(\%)]$ & $9(16)$ & $10(29)$ & $7(15)$ \\
\hline Oral anticoagulation [n, (\%)] & $48(87)$ & $32(94)$ & $1(2)$ \\
\hline LA positivity [n, (\%)] & $42(76)$ & $24(71)$ & $7(15)$ \\
\hline $\begin{array}{l}\text { Anticardiolipin IgG positivity } \\
{[n,(\%)]}\end{array}$ & $26(47)$ & $19(56)$ & $10(21)$ \\
\hline $\begin{array}{l}\text { Anticardiolipin IgM } \\
\text { positivity[n, (\%)] }\end{array}$ & $26(47)$ & $17(50)$ & $11(23)$ \\
\hline Anti- $\beta 2$ GPI IgG positivity [n, (\%)] & $22(40)$ & $11(32)$ & $6(13)$ \\
\hline Anti- $\beta 2$ GPI IgM positivity [ $n,(\%)]$ & $13(24)$ & $10(29)$ & $4(8)$ \\
\hline Double aPL positivity [n, (\%)] & $35(64)$ & $23(68)$ & $9(19)$ \\
\hline Triple aPL positivity [n, (\%)] & $22(40)$ & $14(41)$ & $5(10)$ \\
\hline $\begin{array}{l}\text { Complement C3 levels } \\
\text { (mean } \pm \text { SD) }\end{array}$ & $105 \pm 25$ & $92 \pm 19$ & $87 \pm 26$ \\
\hline $\begin{array}{l}\text { Complement } \mathrm{C} 4 \text { levels } \\
\text { (mean } \pm \text { SD) }\end{array}$ & $20 \pm 8$ & $16 \pm 8$ & $16 \pm 8$ \\
\hline Low complement levels [n, (\%)] & $7(13)$ & $8(24)$ & $13(27)$ \\
\hline Antinuclear antibodies [n, (\%)] & $19(35)$ & $29(85)$ & $39(81)$ \\
\hline SLEDAI (mean \pm SD) & - & $2.61 \pm 1.92$ & $3 \pm 4.48$ \\
\hline History of nephritis [n, (\%)] & - & $6(18)$ & $10(21)$ \\
\hline $\begin{array}{l}\text { History of CNS involvement } \\
{[n,(\%)]}\end{array}$ & - & $8(24)$ & $3(6)$ \\
\hline
\end{tabular}

SD, Standard Deviation; HC, Healthy Controls; APS, Antiphospholipid Syndrome; PAPS, Primary APS; SLE, Systemic Lupus Erythematosus; SLE/APS, Systemic Lupus Erythematosus-associated APS; CVA, Cerebrovascular accident; SLEDAI, SLE Disease Activity Index; CNS, Central Nervous System.

the stepwise backward algorithm $(p=0.1)$ to construct the final multivariate linear regression model, starting from an initial model containing the PAPS-related parameters that demonstrated univariate associations with the type I IFN score at the 0.25 level and adjusting for age and gender. Statistical analysis was performed using STATA version 12.0 (College Station $^{\mathrm{TM}}$, TX, USA) and Graph Pad PRISM software (La Jolla $^{\mathrm{TM}}, \mathrm{CA}$, USA).

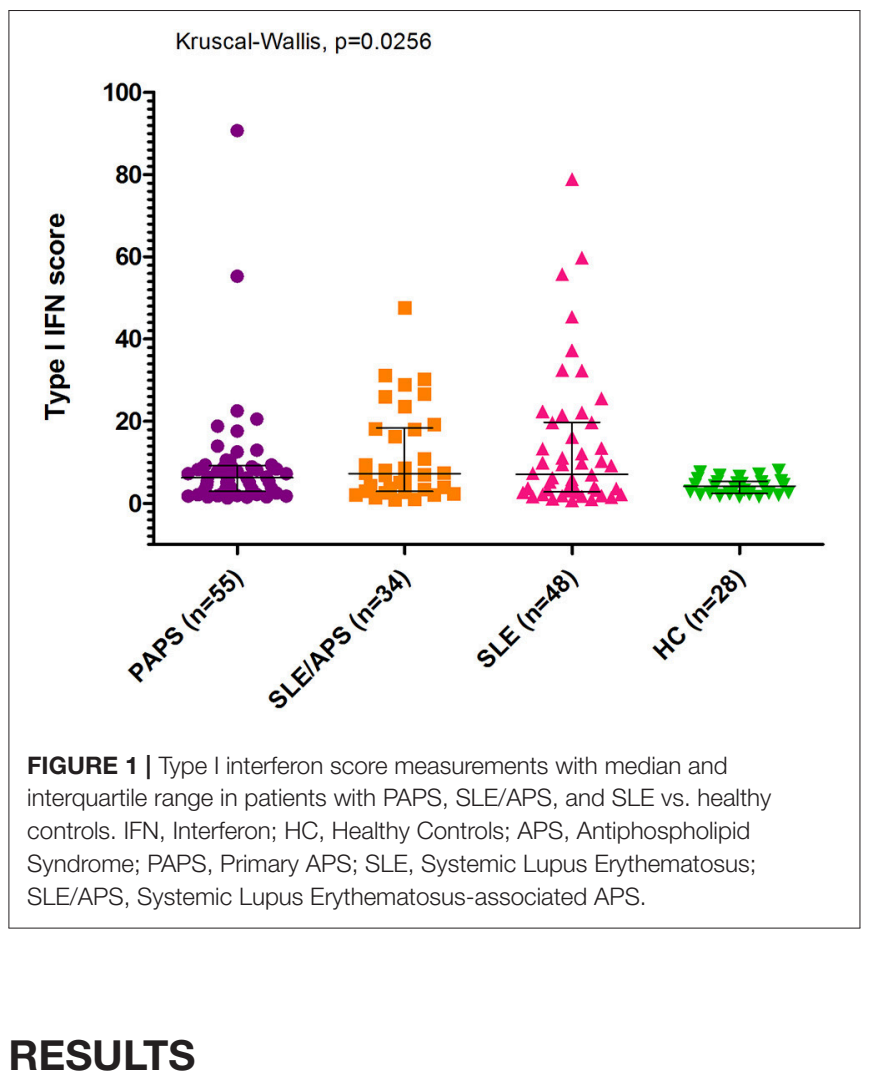

We included in the analysis 55 patients with PAPS, 34 agematched patients with SLE/APS and 48 with SLE/non-APS, and 28 healthy controls. Patient characteristics are shown in Table 1. Female predominance was more pronounced in the SLE group, followed by patients with SLE/APS. The group of PAPS patients characterized by more arterial thrombotic events, recurrent venous or arterial thromboses, and obstetric APS events, but fewer non-criteria APS manifestations than the SLE/APS group. Among patients with PAPS, 35\% had positive ANA in low titers, but none had SLE-specific antibody positivity such as anti-dsDNA or anti-Sm antibodies. None had anti-Ro/SSA or anti-La/SSB antibodies.

The median type I IFN score was highest in patients with SLE/APS (7.2, IQR: 3.0-18.1), followed by patients with SLE (7.1, IQR: 2.7-19.7), PAPS 6.3, IQR: 3.0-9.2), and controls (4.2, IQR: 2.5-5.4) (Figure 1). Mann-Whitney tests for comparison of the type I IFN score in each patient group vs. controls yielded unadjusted $p$-values of 0.014 for PAPS, 0.009 for SLE/APS, and 0.018 for SLE, and multiple-comparison adjusted $p$-values of $0.028,0.027$, and 0.028 , respectively. Among the three genes comprising the type I IFN score, differences between patients and controls were most pronounced in the fold expression of IFI-44 (Figure 2). A high type I IFN signature was observed in $47.92 \%$ of patients with SLE, $44.12 \%$ of SLE/APS, and $38.18 \%$ of patients with PAPS (Figure 3).

Among patients with PAPS, the type I IFN score in univariate analysis was associated with anti- $\beta 2$ GPI antibodies of either IgG or IgM isotype, with a trend for an association with triple aPL positivity (Table 2 ). In multivariate regression, estimates 


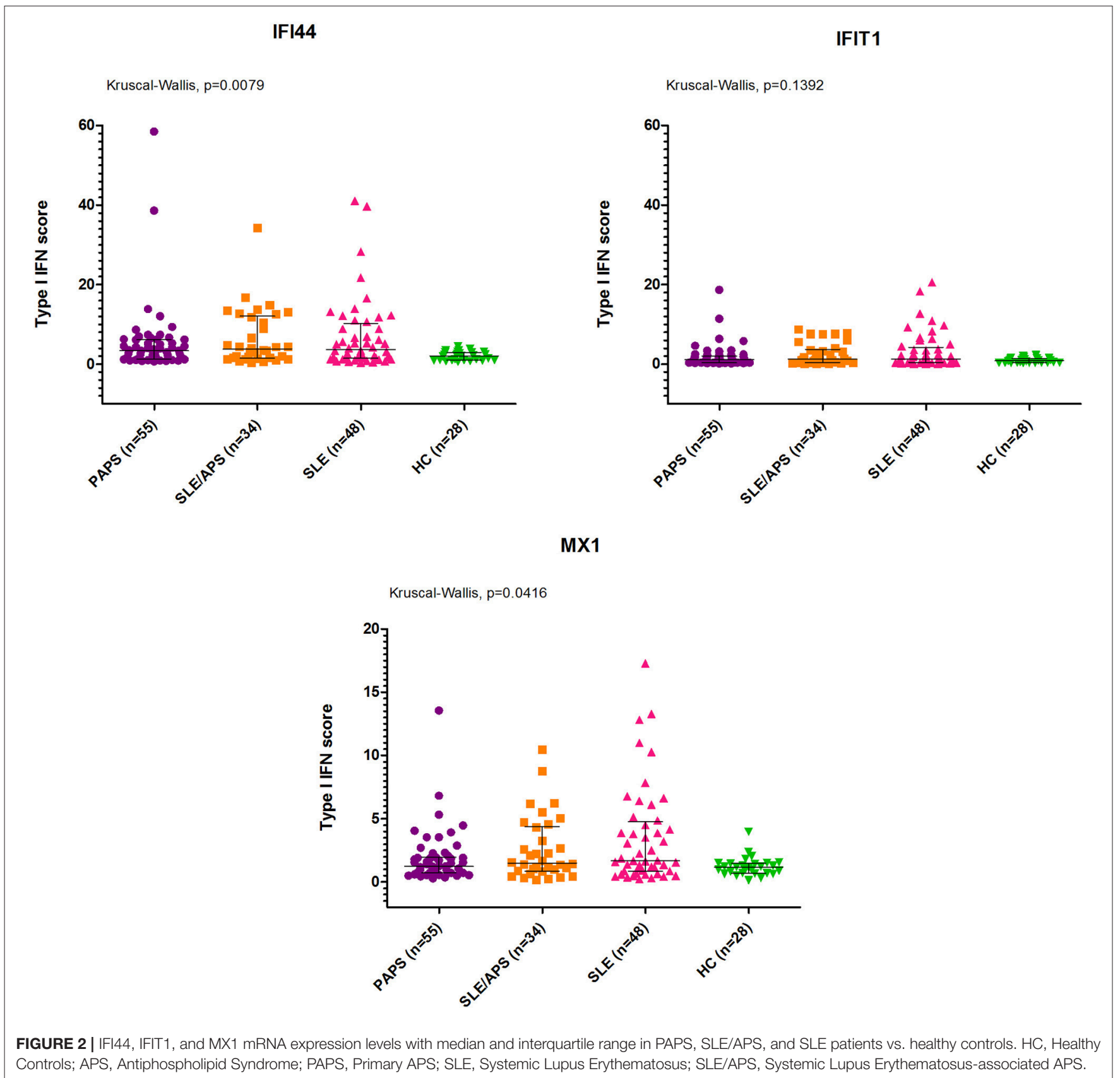

derived from linear regression constructed by applying a stepwise backward algorithm ( $p$ for removal $=0.1$ ) to an initial model including age, gender, arterial events, aCL, anti $32 \mathrm{GPI}$, triple aPL, current use of hydroxycloroquine, and statins. The results of multivariate analysis (Table 3) showed that type I IFN score was significantly higher in females (b-coefficient $=0.49,95 \% \mathrm{CI}$ $(0.04,0.94), p=0.034)$ and patients with medium-to-high IgG or IgM anti- $\beta 2$ GPI antibodies (b-coefficient $=0.53$, 95\% CI $(0.10-$ $0.96), p=0.017$ ), and lower with increasing age (b-coefficient $=-0.02$ per year, 95\% CI: $(-0.04,-0.01), p=0.027)$ and hydroxychloroquine use (b-coefficient $=-0.51,95 \%$ CI $(-0.96$, $-0.06), p=0.027)$.

\section{DISCUSSION}

In this study, we found that patients with PAPS had high type I IFN score relative to controls, and similar to that in SLE and SLE/APS patients. Patients with PAPS with medium-to-high anti$\beta 2$ GPI antibody titers of either IgG or IgM isotype had higher IFN scores, whereas those treated with hydroxychloroquine had lower scores, after adjusting for age and gender and other APSrelated factors.

The findings of high type I IFN score in patients with PAPS vs. controls, and in comparable levels to that in SLE and SLE/APS patients, indicate that inflammatory pathways 


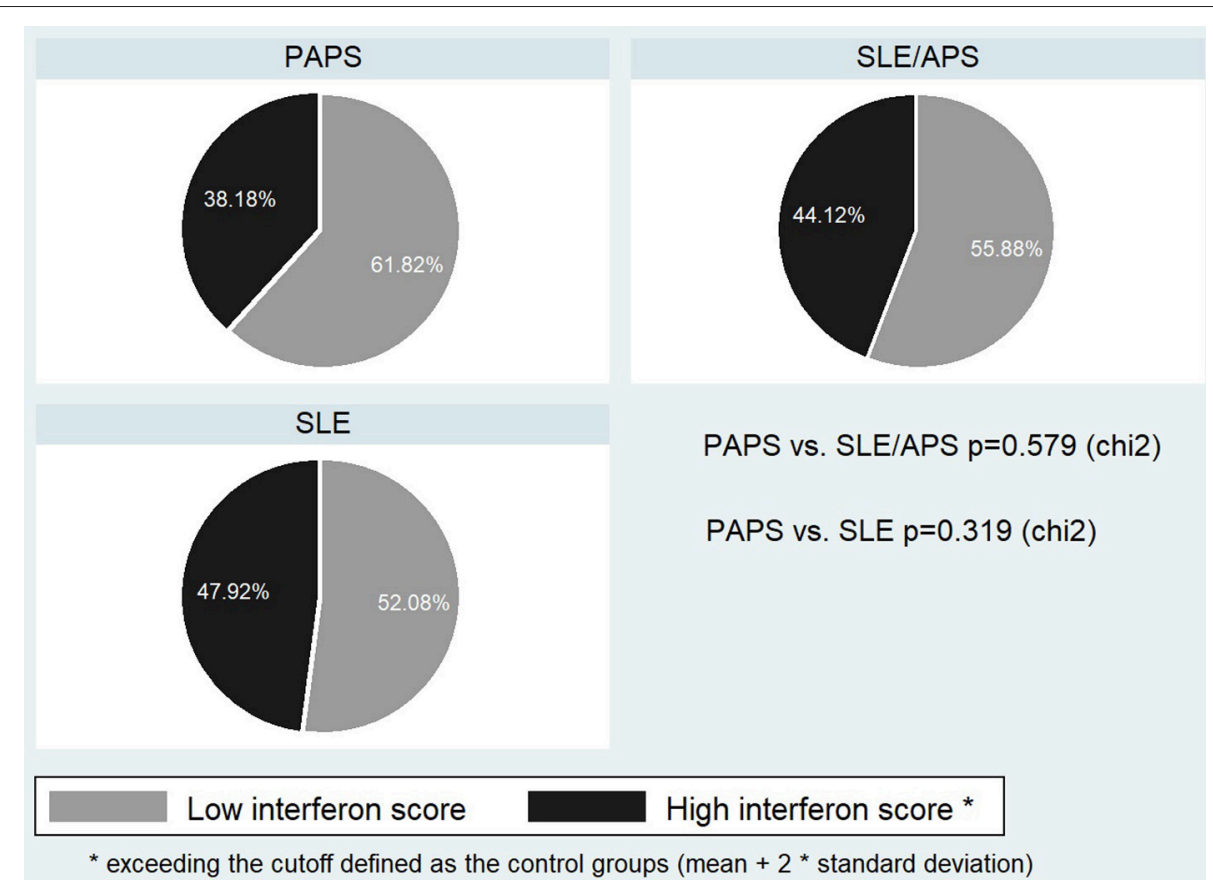

FIGURE 3 | Frequency of high type I IFN score in PAPS, SLE, and SLE/APS groups. APS, Antiphospholipid Syndrome; PAPS, Primary APS; SLE, Systemic Lupus Erythematosus; SLE/APS, Systemic Lupus Erythematosus-associated APS.

TABLE 2 | Univariate associations between type I interferon score and disease-related factors in patients with PAPS.

\begin{tabular}{|c|c|c|c|}
\hline \multirow[t]{2}{*}{ Disease-related factor } & \multicolumn{2}{|c|}{ Type I interferon score median, (interquartile range) } & \multirow[t]{2}{*}{$p$-value* } \\
\hline & Factor absent & Factor present & \\
\hline Age $>44$ years\# & $6.45(3.63-9.38)$ & $5.13(2.11-8.41)$ & 0.125 \\
\hline Female gender & $4.99(2.54-8.41)$ & $6.82(3.56-9.38)$ & 0.239 \\
\hline Arterial thrombotic events & $7.55(2.98-12.97)$ & $5.30(2.95-8.41)$ & 0.223 \\
\hline Non-criteria APS manifestations & $6.45(2.54-9.36)$ & $5.28(3.56-8.38)$ & 0.733 \\
\hline Recurrent thrombotic events & $6.44(2.66-9.88)$ & $5.30(3.56-8.41)$ & 0.682 \\
\hline Obstetric APS complications & $6.27(3.56-17.61)$ & $4.99(2.37-8.41)$ & 0.277 \\
\hline aCL positivity & $3.05(1.82-9.18)$ & $6.45(3.63-8.92)$ & 0.122 \\
\hline Anti- $\beta 2 \mathrm{GPI}$ positivity & 4.99 (1.94-8.7) & $8.00(4.30-9.37)$ & 0.045 \\
\hline LA positivity & $7.21(2.17-8.70)$ & 5.92 (3.55-9.38) & 0.663 \\
\hline Triple aPL positivity & $4.99(2.11-8.78)$ & 7.54 (5.03-9.38) & 0.057 \\
\hline Hydroxychloroquine use & $8.00(4.15-9.38)$ & 5.30 (2.95-8.38) & 0.231 \\
\hline Antiplatelet use & $6.44(2.54-8.78)$ & $5.92(3.55-9.88)$ & 0.602 \\
\hline Statin use & 6.83 (3.55-9.36) & $3.63(1.94-5.30)$ & 0.101 \\
\hline
\end{tabular}

${ }^{*} P$-value derived from Mann-Whitney $U$.

\#CUt off selected to coincide with the median age in the PAPS group.

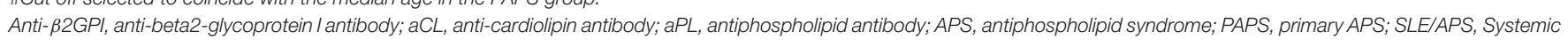
Lupus Erythematosus-associated APS.

involving type I IFN may be implicated in the pathophysiology of APS, independently of SLE co-existence. Our findings are congruent to those of previous studies on type I IFN signature in PAPS. Bernales and colleagues reported for the first time high type I IFN signature in a small series of 13 PAPS and 17 SLE patients compared to controls (15). Grenn and colleagues found elevated levels of the IFN-inducible genes IFIT-1, IFI44, and PRKR in PBMCs and sera from 42 PAPS patients, and in serum samples from an independent cohort of 26 patients with PAPS (16). Van den Hoogen and colleagues showed that type I IFN score was higher in 24 patients with PAPS than controls, but lower compared to 47 patients with SLE and 28 with SLE/APS (17). Recently, Knight and colleagues demonstrated a proinflammatory gene expression signature in PAPS using 
TABLE 3 | Multivariate linear regression model of clinical and laboratory determinants of log-transformed type I interferon score in patients with PAPS.

\begin{tabular}{lccc}
\hline Parameter & $\boldsymbol{\beta}$ coefficient & 95\% confidence interval & $\boldsymbol{P}$-value \\
\hline Age (per year) & -0.02 & $-0.04,-0.02$ & 0.027 \\
Female gender & 0.49 & $0.04,0.94$ & 0.034 \\
Hydroxychloroquine use & -0.51 & $-0.95,-0.06$ & 0.027 \\
Anti- $\beta 2$ GPI positivity & 0.53 & $0.10,0.96$ & 0.017 \\
\hline
\end{tabular}

Anti- $\beta 2$ GPI, anti-beta2-glycoprotein I antibody; PAPS, primary APS.

RNA sequencing, mainly driven by up-regulation of type I IFNinducible genes and more specifically by high transcription of IFIT-1 and MX-1 (22), which was also highly expressed in our patients with PAPS.

In our PAPS patients, anti- $\beta 2 \mathrm{GPI}$ antibodies were significantly correlated with type IFN scores. Our findings are in accordance with those of Grenn and colleagues, showing a significant correlation between anti- $\beta 2$ GPI positivity and elevated levels of IFIT-1 and IFI44 in PBMCs of PAPS patients (16). Basic research findings also support that aPL can induce IFN $\alpha$ production in cell cultures from pDCs from patients with APS (23). Furthermore, antibodies to $\beta 2 \mathrm{GPI}$, especially to domain I of $\beta 2 \mathrm{GPI}$, emerge in current research as one of the main pathogenic autoantibody subsets in APS associated with several phenotypes in the APS spectrum (24).

We also found that hydroxychloroquine use is associated with significantly lower type I IFN scores in patients with PAPS, confirming the results by van den Hoogen and colleagues (17). Hydroxychloroquine can attenuate the IFN signature via modulating Toll-like receptor (TLR) signaling and blocking neutrophil extracellular traps activity (22, 25). Hydroxychloroquine in patients with PAPS is the object of rigorous investigation, and promising evidence currently exists for its role in aPL production (26), and prevention of thrombotic $(6,27,28)$ and obstetric event recurrences (29-31).

Although anticoagulation is the mainstay of treatment for APS, several patients experience recurrent thrombotic events and pregnancy morbidity despite the use of conventional treatments. In addition, anticoagulation is largely ineffective for non-criteria APS-related manifestations (5), which may be better addressed by alternative treatments targeting inflammatory pathways. Grenn and colleagues recently demonstrated that the impaired ability of endothelial progenitors to differentiate into endothelial cells was reversed by a type I IFN receptor-neutralizing antibody (16). Further research into IFN-inducible gene expression (including both type I and II IFN signature) and inflammatory dysregulation in APS could pave the way for new emerging therapies in APS potentially including interferon-blocking agents.

\section{REFERENCES}

1. Miyakis S, Lockshin MD, Atsumi T, Branch DW, Brey RL, Cervera R, et al. International consensus statement on an update of the classification criteria for definite antiphospholipid syndrome (APS). J Thromb Haemost. (2006) 4:295-306. doi: 10.1111/j.1538-7836.2006.01753.x
Our study has certain limitations. Due to the rarity of APS, the sample size was not adequate to support multivariate models which would include all individual APS-related parameters potentially affecting the type I IFN score, and power to detect weaker associations may be limited. Nevertheless, our results are derived from a cohort of well-characterized and closely monitored patients, and this is the first study to show a multivariate association between high IFN signature and anti- $\beta 2$ GPI antibody positivity in patients with APS, while adjusting for age, gender, and other significant diseaserelated factors.

In conclusion, patients with PAPS are characterized by a high type I interferon signature, which seems to be more pronounced in those with anti- $\beta 2$ GPI positivity, and limited in those receiving hydroxychloroquine treatment. Our findings highlight the need for further investigation of IFN pathways in PAPS, aiming to elucidate their role in the pathogenesis of thrombotic and non-thrombotic complications and investigate their potential as therapeutic targets for selected patients.

\section{DATA AVAILABILITY}

The datasets generated for this study are available on request to the corresponding author.

\section{ETHICS STATEMENT}

This study was carried out in accordance with the recommendations of local IRB ("Laikon Hospital Scientific Council”) with written informed consent from all subjects. All subjects gave written informed consent in accordance with the Declaration of Helsinki. The protocol was approved by the Laikon Hospital Scientific Council.

\section{AUTHOR CONTRIBUTIONS}

MT conceived the original idea, supervised and interpreted the findings of this work, and the manuscript writing. EP performed the experiments and wrote the manuscript. EK contributed to sample preparation, performed the statistical analysis, and helped to draft the manuscript. All authors provided critical feedback and helped shape the research, analysis, and manuscript.

\section{FUNDING}

This work was supported by the Special Account for Research Grants of the National and Kapodistrian University of Athens Medical School, Greece (Grant no. 11123).
2. Petri M. Update on anti-phospholipid antibodies in SLE: the Hopkins' Lupus Cohort. Lupus. (2010) 19:419-23. doi: 10.1177/0961203309360541

3. Cervera R, Serrano R, Pons-Estel GJ, Ceberio-Hualde L, Shoenfeld Y, de Ramon E, et al. Morbidity and mortality in the antiphospholipid syndrome during a 10-year period: a multicentre prospective study of 1000 patients. Ann Rheum Dis. (2015) 74:1011-8. doi: 10.1136/annrheumdis-2013-204838 
4. Abreu MM, Danowski A, Wahl DG, Amigo MC, Tektonidou M, Pacheco MS, et al. The relevance of "non-criteria" clinical manifestations of antiphospholipid syndrome: 14th International Congress on Antiphospholipid Antibodies Technical Task Force Report on Antiphospholipid Syndrome Clinical Features. Autoimmun Rev. (2015) 14:401-14. doi: 10.1016/j.autrev.2015.01.002

5. Tektonidou MG. Antiphospholipid syndrome nephropathy: from pathogenesis to treatment. Front Immunol. (2018) 9:1181. doi: 10.3389/fimmu.2018.01181

6. Andrade D, Tektonidou M. Emerging therapies in antiphospholipid syndrome. Curr Rheumatol Rep. (2016) 18:22. doi: 10.1007/s11926-016-0566-z

7. Brkic Z, Maria NI, van Helden-Meeuwsen CG, van de Merwe JP, van Daele PL, Dalm VA, et al. Prevalence of interferon type I signature in CD14 monocytes of patients with Sjogren's syndrome and association with disease activity and BAFF gene expression. Ann Rheum Dis. (2013) 72:728-35. doi: 10.1136/annrheumdis-2012-201381

8. Mavragani CP, Crow MK. Activation of the type I interferon pathway in primary Sjogren's syndrome. J Autoimmun. (2010) 35:225-31. doi: 10.1016/j.jaut.2010.06.012

9. Higgs BW, Liu Z, White B, Zhu W, White WI, Morehouse C, et al. Patients with systemic lupus erythematosus, myositis, rheumatoid arthritis and scleroderma share activation of a common type I interferon pathway. Ann Rheum Dis. (2011) 70:2029-36. doi: 10.1136/ard.2011.150326

10. Lee PY, Li Y, Richards HB, Chan FS, Zhuang H, Narain S, et al. Type I interferon as a novel risk factor for endothelial progenitor cell depletion and endothelial dysfunction in systemic lupus erythematosus. Arthritis Rheum. (2007) 56:3759-69. doi: 10.1002/art.23035

11. Rodriguez-Carrio J, de Paz B, Lopez P, Prado C, Alperi-Lopez M, BallinaGarcia FJ, et al. IFNalpha serum levels are associated with endothelial progenitor cells imbalance and disease features in rheumatoid arthritis patients. PLoS ONE. (2014) 9:e86069. doi: 10.1371/journal.pone.0086069

12. Baechler EC, Batliwalla FM, Karypis G, Gaffney PM, Ortmann WA, Espe KJ, et al. Interferon-inducible gene expression signature in peripheral blood cells of patients with severe lupus. Proc Natl Acad Sci USA. (2003) 100:2610-5. doi: $10.1073 /$ pnas.0337679100

13. Bennett L, Palucka AK, Arce E, Cantrell V, Borvak J, Banchereau J, et al. Interferon and granulopoiesis signatures in systemic lupus erythematosus blood. J Exp Med. (2003) 197:711-23. doi: 10.1084/jem.20021553

14. Lauwerys BR, Ducreux J, Houssiau FA. Type I interferon blockade in systemic lupus erythematosus: where do we stand? Rheumatology. (2014) 53:1369-76. doi: 10.1093/rheumatology/ket403

15. Bernales I, Fullaondo A, Marin-Vidalled MJ, Ucar E, Martinez-Taboada V, Lopez-Hoyos $\mathrm{M}$, et al. Innate immune response gene expression profiles characterize primary antiphospholipid syndrome. Genes Immun. (2008) 9:3846. doi: 10.1038/sj.gene.6364443

16. Grenn RC, Yalavarthi S, Gandhi AA, Kazzaz NM, Nunez-Alvarez C, Hernandez-Ramirez D, et al. Endothelial progenitor dysfunction associates with a type I interferon signature in primary antiphospholipid syndrome. Ann Rheum Dis. (2017) 76:450-7. doi: 10.1136/annrheumdis-2016-209442

17. van den Hoogen LL, Fritsch-Stork RD, Versnel MA, Derksen RH, van Roon JA, Radstake TR. Monocyte type I interferon signature in antiphospholipid syndrome is related to proinflammatory monocyte subsets, hydroxychloroquine and statin use. Ann Rheum Dis. (2016) 75:e81. doi: 10.1136/annrheumdis-2016-210485

18. Hochberg MC. Updating the American College of Rheumatology revised criteria for the classification of systemic lupus erythematosus. Arthritis Rheum. (1997) 40:1725. doi: 10.1002/art.1780400928

19. Devreese KMJ, Ortel TL, Pengo V, de Laat B. Laboratory criteria for antiphospholipid syndrome: communication from the SSC of the ISTH. $J$ Thromb Haemost. (2018) 16:809-13. doi: 10.1111/jth.13976
20. Nezos A, Gravani F, Tassidou A, Kapsogeorgou EK, Voulgarelis M, Koutsilieris M, et al. Type I and II interferon signatures in Sjogren's syndrome pathogenesis: contributions in distinct clinical phenotypes and Sjogren's related lymphomagenesis. J Autoimmun. (2015) 63:47-58. doi: 10.1016/j.jaut.2015.07.002

21. Kirou KA, Gkrouzman E. Anti-interferon alpha treatment in SLE. Clin Immunol. (2013) 148:303-12. doi: 10.1016/j.clim.2013.02.013

22. Knight JS, Meng H, Coit P, Yalavarthi S, Sule G, Gandhi AA, et al. Activated signature of antiphospholipid syndrome neutrophils reveals potential therapeutic target. JCI Insight. (2017) 2:93897. doi: 10.1172/jci.insight. 93897

23. Prinz N, Clemens N, Strand D, Putz I, Lorenz M, Daiber A, et al. Antiphospholipid antibodies induce translocation of TLR7 and TLR8 to the endosome in human monocytes and plasmacytoid dendritic cells. Blood. (2011) 118:2322-32. doi: 10.1182/blood-2011-01-330639

24. Meroni PL. Anti-beta-2 glycoprotein I epitope specificity: from experimental models to diagnostic tools. Lupus. (2016) 25:905-10. doi: 10.1177/0961203316641772

25. Mitsios A, Arampatzioglou A, Arelaki S, Mitroulis I, Ritis K. NETopathies? Unraveling the dark side of old diseases through neutrophils. Front Immunol. (2016) 7:678. doi: 10.3389/fimmu.2016.00678

26. Nuri E, Taraborelli M, Andreoli L, Tonello M, Gerosa M, Calligaro A, et al. Long-term use of hydroxychloroquine reduces antiphospholipid antibodies levels in patients with primary antiphospholipid syndrome. Immunol Res. (2017) 65:17-24. doi: 10.1007/s12026-016-8812-z

27. Schmidt-Tanguy A, Voswinkel J, Henrion D, Subra JF, Loufrani L, Rohmer V, et al. Antithrombotic effects of hydroxychloroquine in primary antiphospholipid syndrome patients. J Thromb Haemost. (2013) 11:1927-9. doi: $10.1111 /$ jth. 12363

28. Erkan D, Unlu O, Sciascia S, Belmont HM, Branch DW, Cuadrado MJ, et al. APS ACTION. Hydroxychloroquine in the primary thrombosis prophylaxis of antiphospholipid antibody positive patients without systemic autoimmune disease. Lupus. (2018) 27:399-406. doi: 10.1177/09612033177 24219

29. Bertolaccini ML, Contento G, Lennen R, Sanna G, Blower PJ, Ma MT, et al. Complement inhibition by hydroxychloroquine prevents placental and fetal brain abnormalities in antiphospholipid syndrome. J Autoimmun. (2016) 75:30-8. doi: 10.1016/j.jaut.2016.04.008

30. Sciascia S, Branch DW, Levy RA, Middeldorp S, Pavord S, Roccatello $\mathrm{D}$, et al. The efficacy of hydroxychloroquine in altering pregnancy outcome in women with antiphospholipid antibodies. Evidence and clinical judgment. Thromb Haemost. (2016) 115:285-90. doi: 10.1160/th15-0 6-0491

31. Mekinian A, Alijotas-Reig J, Carrat F, Costedoat-Chalumeau N, Ruffatti A, Lazzaroni MG, et al. on the behalf of the SNFMI and the European Forum on Antiphospholipid Antibodies. Refractory obstetrical antiphospholipid syndrome: features, treatment and outcome in a European multicenter retrospective study. Autoimmun Rev. (2017) 16:730-73. doi: 10.1016/j.autrev.2017.05.006

Conflict of Interest Statement: The authors declare that the research was conducted in the absence of any commercial or financial relationships that could be construed as a potential conflict of interest.

Copyright (c) 2019 Palli, Kravvariti and Tektonidou. This is an open-access article distributed under the terms of the Creative Commons Attribution License (CC BY). The use, distribution or reproduction in other forums is permitted, provided the original author(s) and the copyright owner(s) are credited and that the original publication in this journal is cited, in accordance with accepted academic practice. No use, distribution or reproduction is permitted which does not comply with these terms. 